\title{
Enhanced expression of SOS1 is detected in prostate cancer epithelial cells from African-American men
}

\author{
OLGA A. TIMOFEEVA ${ }^{1}$, XUEPING ZHANG ${ }^{1}$, HABTOM W. RESSOM ${ }^{1}$, RENCY S. VARGHESE ${ }^{1}$, \\ BHASKAR VS. KALLAKURY ${ }^{1}$, KAN WANG ${ }^{1}$, YOUNGMI JI ${ }^{2}$, AMRITA CHEEMA ${ }^{1}$, MIRA JUNG ${ }^{1}$, \\ MILTON L. BROWN ${ }^{1}$, JOHNG S. RHIM ${ }^{2}$ and ANATOLY DRITSCHILO ${ }^{1}$
}

\author{
${ }^{1}$ Vincent T. Lombardi Comprehensive Cancer Center, Georgetown University School of Medicine, Washington, DC 20057; \\ ${ }^{2}$ Center for Prostate Disease Research, Uniformed Services University of the Health Sciences, Bethesda, MD 20814, USA
}

Received May 25, 2009; Accepted July 2, 2009

DOI: 10.3892/ijo_00000388

\begin{abstract}
African-American (AA) men experience an increased risk of developing prostate cancers as well as increased mortality following treatment as compared to European-American (EA) men. The aim of our study was to identify biological factors with the potential to predispose AA men to prostate tumor progression and metastasis. To identify cancer-specific gene expression patterns in AA men, we established primary prostate cancer epithelial cells from $14 \mathrm{AA}$ and 13 EA men. High-throughput microarrays were used to investigate differences in global gene expression comparing the two groups. Quantitative RT-PCR and immunohistochemistry validated mRNA and protein expression levels. RNAi knockdowns provided support for biological significance for the identified genes in prostate cancer cells. Son of sevenless homolog 1 (SOS1) was overexpressed in AA male-derived primary prostate cancer epithelial cells. Depletion of SOS1 in PC3 and DU145 prostate cancer cells resulted in decreased capacities for cell proliferation, migration and invasion, at least partially through inhibition of extracellular signal-regulated kinase 1 and 2. Tissue microarray analyses of SOS1 expression in prostate carcinomas correlated with Gleason's grades of tumors, consistent with a possible role in prostate cancer progression. Investigation of prostate cancer-derived epithelial cells has led to identification of SOS1 as a potential candidate biomarker and molecular therapeutic target in prostate cancer in AA men, consistent with the hypothesis that a biological basis exists for prostate cancer aggressiveness in AA men.
\end{abstract}

Correspondence to: Dr Anatoly Dritschilo, TRB, R. E221, Vincent T. Lombardi Comprehensive Cancer Center, Georgetown University School of Medicine, 3900 Reservoir Rd NW, Washington, DC 20057, USA

E-mail: dritscha@georgetown.edu

Key words: prostate cancer, African-American men, global mRNA expression profiling, migration and survival

\section{Introduction}

Prostate cancer is the most frequently diagnosed solid malignancy in American men and results in approximately 30,000 deaths annually (1). Comparisons of population-based registries consistently show that African-American (AA) men have the highest age-adjusted incidence (2). In the period 1996-2000, AA men had an age-adjusted incidence 1.6 times higher than that of European-American (EA) men (3). In addition, AA men have worse overall survival (risk ratio $1.35,95 \%$ CI $1.23-1.48$ ) (4). The reasons for elevated incidence and poorer prognosis in AA men are not clear. Differences in access to health care and management of local disease, and differences in disease biology have been suggested (5). However, recent studies have adjusted for socioeconomic variables, but continue to find an increased risk among AA men for prostate cancer-specific survival and biochemical recurrences (4-9). Therefore, examination of the potential biological differences offers an approach to identify and reduce this health disparity.

Previous investigations have identified genetic factors with the potential for increasing prostate cancer incidence and mortality in AA, suggesting differences in tumor biology (10-13). Such studies have addressed differences in the distributions of known or suspected risk factors among racial groups. Efforts to correlate more aggressive biology with racial differences have included whole-genome prostate cancer association studies which have identified susceptibility loci for prostate cancer (14-16). Increased androgen levels and androgen receptor expression have been implicated in the development and rapid progression of prostate cancer in AA (17-19). Also, higher levels of insulin-like growth factor-I and lower levels of IGF binding protein-3 have been associated with an increased risk of prostate cancer (20). However, such studies have not identified the presumed cancer-relevant genes, and the reasons for increased prostate cancer risk in the AA population remain to be defined.

Three reported studies have used gene expression profiling to compare prostate tissue from AA and EA patients (21-23). The study by Haqq et al compared gene expression in non-neoplastic prostate tissues from various ethnic groups (21). No cluster node distinguished non-cancerous prostate 
tissue of AA from EA men, although differential expression levels of estrogen receptor $\alpha(\mathrm{ER} \alpha)$ were observed in the stroma (21). The study by Wallace et al analyzed differences in gene expression in prostate tumors from 33 AfricanAmerican and 36 European-American men (22). This analysis revealed higher expression of genes that influence immune responses and metastasis in the tumors of African-American men compared with European-American men. Among the genes showing elevated expression in prostate tumors from African-American men were AMFR, CXCR4, and MMP9, all of which have been linked to cancer metastasis (22). The study mostly detected differential expression of immune responsive genetic programs in African-American as compared to European-American patients that offer potentially important leads for understanding the disease (22). The most recent study by Reams et al compared gene expression profiling in tumors with a Gleason's score of 6 from AfricanAmerican males to prostate tumors in European-American males (23). This study also showed that the gene ontology terms prevalent in African-American male prostate tumor/ normal ratios included interleukins, progesterone signaling, chromatin-mediated maintenance and myeloid dendritic cell proliferation (23).

The high degree of heterogeneity of prostate tissue presents a challenge for molecular studies of prostate cancer. The analysis of tumor tissues offers insight into contributions by both epithelial and stomal components; however, the presence of fibroblasts, inflammatory cells, and vascular endothelial cells increases the complexity in interpreting expressed gene patterns and must be taken into account when performing high-throughput analyses. Moreover, representation of each cell type within a given sample determines the overall expression profile and makes it difficult to compare prostate samples with varying epithelial and stromal contents (24). In this study we established primary cell strains from radical prostatectomy specimens of AA and EA men, which were matched for tumor stage and Gleason's grade. Global gene expression analyses in these primary epithelial cells showed increased levels of expression of genes associated with growth, migration and invasion in AA as compared to EA men suggesting a difference in epithelial cancer cell biology. Our examination of the roles of these genes in modifying cellular characteristics demonstrated enhanced growth and migration of prostate cancer cells, consistent with a more 'aggressive' phenotype.

\section{Materials and methods}

Generation of primary cell culture. The malignant tissues from African-American and European-American men used for generating primary cultures were obtained from radical prostatectomy specimens according to Walter Reed Medical Center and Uniformed Services University of the Health Sciences Internal Review Board approved protocols. The presence of prostatic adenocarcinoma was confirmed by light microscopy. Fresh prostatectomy tissue specimens were obtained under sterile conditions by an experienced pathologist. Tumor tissue on gross inspection was dissected separately for the purpose of generating a cell culture. The method for generating primary cell cultures has been previously described $(25,26)$. Briefly, minced pieces of tissues were distributed to several collagen-coated cell culture dishes with keratinocyte serum-free medium (K-SFM) (Life Technologies, Inc., Gaithersburg, MD) supplemented with $5 \%$ fetal bovine serum. The serum was used to stimulate primary prostate epithelial cells in culture (27). Tissue explants were grown for three weeks until reaching confluence. Aliquots of the primary cultures were then frozen and stored in liquid nitrogen until the cells were reestablished in secondary culture.

Cell growth and maintenance. Reconstituted primary cells were cultured for $<5$ passages. Cells were grown to the same confluence $(\sim 80 \%)$ in K-SFM supplemented with bovine pituitary extract and recombinant epidermal growth factor (Life Technologies, Inc.). Cells from 28 patients were expanded and 27 (14 AA and 13 EA) yielded sufficient cell numbers for gene expression studies.

Affymetrix microarray analysis. Total RNA was extracted using an RNeasy Kit (Qiagen, Valencia, CA, USA). RNA labeling and hybridization were performed according to Affymetrix standard protocol for one-cycle target labeling method. Fragmented cRNA was hybridized in triplicates to Affymetrix GeneChip HG-U133A 2.0 arrays (Affymetrix, Santa Clara, CA).

Data analysis, bioinformatics, and statistics. Affymetrix microarray data were analyzed to identify differentially expressed genes in the epithelial cells from the cohorts of AA $(n=14)$ and EA $(n=13)$ prostate cancer patients. Affymetrix data analysis included pre-processing of the probe-level Affymetrix data (CEL files). We applied RMA for background adjustment, quantile method for normalization, and the 'median polish' for summarization. The triplicate arrays representing the same subject were averaged. The random variance model implemented in BRB-ArrayTools (NCI, Bethesda, MD) was used for this analysis (28). Probe sets were considered statistically significant at a p-value $<0.001$. For each gene, BRB-ArrayTools calculated the false discovery rate (FDR), which is defined as the median number of falsepositive genes divided by the number of significant genes. We also used BRB-ArrayTools to determine the most enriched binding sites in the promoters of differentially expressed genes. Pathway analysis was performed with Database for Annotation, Visualization and Integrated Discovery (DAVID) (29).

Quantitative $R T-P C R$. Total RNA extracted from primary cell strains (8 strains for each group) was reverse-transcribed using the High Capacity cDNA Reverse Transcription Kit (Applied Biosystems). Quantitative real-time PCR (qRTPCR) was performed in triplicate using TaqMan Gene Expression Assays (Applied Biosystems) on the Applied Biosystems 7900HT Fast Real-time PCR System using standard mode. The assay ID numbers of the validated genes were as follows: autocrine mobility factor receptor (AMFR), Hs00181609_m1; cathepsin B (CTSB), Hs00947439_m1; catenin (cadherin-associated protein), $31,88 \mathrm{kDa}$ (CTNNB1), Hs00170025_m1; son of sevenless homolog 1 (SOS1), Hs00362308_m1; metastasis-associated 1 family, 
member 2 (MTA2), Hs00191018 m1; homeodomaininteracting protein kinase 3 (HIPK3), Hs00178628 m1; and cyclin D2 (CCND2), Hs00277041_m1. Amplification of 18S rRNA was used as an endogenous control to standardize the amount of sample added to the reaction. The comparative cycle threshold (CT) method was used to analyze the data by generating relative values of the amount of target cDNA (Applied Biosystems). CT represents the number of cycles for the amplification of the target to reach a fixed threshold and correlates with the amount of starting material present. To obtain relative values, the following arithmetic formula was used: $2-\Delta \Delta \mathrm{CT}$, where $\Delta \mathrm{CT}$ is the difference between the threshold cycles of the target and an endogenous reference (18S), and $-\triangle \Delta C T$ is the difference between $\Delta C \mathrm{C}$ of the target sample (AA) and a designated calibrator (EA). The statistical analyses of these data were performed with a two-sided t-test when the expression data showed normal distribution; otherwise the Wilcoxon Rank-Sum test was applied.

Immunohistochemistry. AMFR, SOS1, and MTA2 protein distributions in prostate tissues were determined by immunohistochemical staining of two normal and three prostate tumor tissues. Sections $(5 \mu \mathrm{m})$ from formalin-fixed paraffinembedded tissues were deparaffinized with xylenes and rehydrated through a graded alcohol series. Antigen retrieval was performed by immersing the tissue sections at $98^{\circ} \mathrm{C}$ for $20 \mathrm{~min}$ in $10 \mathrm{mM}$ citrate buffer $(\mathrm{pH} 6.0)$ with $0.05 \%$ Tween. Immunohistochemical staining was performed using the Histostain Plus kit from Zymed according to the manufacturer's instructions. Briefly, slides were exposed to $1 / 50$, $1 / 100$, and 1/100 dilutions of primary antibodies for AMFR, SOS1 and MTA2 (Santa Cruz Biotechnology, Santa Cruz, $\mathrm{CA})$ respectively for $1 \mathrm{~h}$ at room temperature (RT), and biotin-conjugated broad spectrum secondary antibodies were applied. Horseradish peroxidase-conjugated streptavidin was added for $10 \mathrm{~min}$ at RT, and HRP was detected by DAB (Dako). Slides were counterstained with hematoxylin (Fisher, Harris Modified Hematoxylin) at a 1:17 dilution for 2 min at $\mathrm{RT}$, blued in $1 \%$ ammonium hydroxide for $1 \mathrm{~min}$ at RT, dehydrated, and mounted with Permount. Consecutive tumor sections with the omitted primary antibody were used as negative controls. Images were captured using an Olympus DP70 microscope at x40 magnification.

Prostate cancer TMAs containing 33 cases/63 cores (BC19012) were purchased from US Biomax, Rockville, MD and processed according to the manufacturer's recommendations. Three TMA slides were stained with each antibody. The intensity and extent of the immunoreactivity were microscopically evaluated in each core on three slides by a pathologist (B.VS.K.) experienced in diagnosing prostate carcinoma. Staining intensity was scored on an arbitrary 0 to $3+$ scale, with 0 indicating no or trace staining and grades $1+$ to $3+$ representing increasing intensity. The extent of positive intracytoplasmic staining was evaluated in a semiquantitative manner. Scoring was based on the percentage of stained epithelial cells and graded from 0 to 3, signifying $0-4 \%$, $5-25 \%, 26-50 \%$ and $>50 \%$, respectively.

siRNA knockdown. Stealth RNAi (RNAi) to silence the expression of AMFR or SOS1 and non-specific Block-it
RNA were obtained from Invitrogen (Carlsbad, CA). The controls included non-silencing Cy3-labeled siRNA and Cy3-labeled GAPDH siRNA, obtained from Qiagen (Austin, TX). PC3 cells were transfected with $10-50 \mathrm{nM}$ siRNA. Transfection was performed using Trans-TKO reagent from Mirus (Madison, WI) according to the manufacturer's instructions. Total RNA and protein were extracted 24, 48, 72 and $96 \mathrm{~h}$ and 7 days after transfection. The SOS1 and AMFR mRNA levels were measured by qRT-PCR using TaqMan Gene Expression Assays (Applied Biosystems) on the Applied Biosystems 7900HT Fast Real-time PCR System using standard mode as described above. Western blot analysis was performed with anti-AMFR and anti-SOS1 antibodies from Santa Cruz Biotechnology.

Cell proliferation and FACS analysis of cell cycle. PC3 and DU145 cells were seeded at $0.3 \times 10^{5}$ per well in 6-well plates and maintained in RPMI medium supplemented with $10 \%$ FBS for $24 \mathrm{~h}$ before being transfected with RNAi. Two days after the RNAi treatments, cells were re-plated at $0.2 \times 10^{5}$ per well in 6-well plates. Cell proliferation rates were measured by cell counting of samples in triplicate every 2 days. For flow cytometry, cells were cultured for $72 \mathrm{~h}$ after RNAi transfection, fixed in $70 \%$ ethanol, stained with propidium iodide, and analyzed for cell cycle distribution by FACScan as previously described (30).

Wound healing assay. Cells were allowed to grow to complete confluence and then starved in low serum $(0.5 \%)$ for $24 \mathrm{~h}$. Subsequently, a plastic pipette tip was used to scratch the cell monolayer to create a cleared area, and the wounded cell layer was washed with fresh medium to remove loose cells. Immediately following scratch wounding $(0 \mathrm{~h})$ and after incubation of cells at $37^{\circ} \mathrm{C}$ for $20 \mathrm{~h}$, phase-contrast images (x10 field) of the wound healing process were photographed digitally with an inverted microscope (Olympus IX50). The distances of the wound areas were measured on the images, set at $100 \%$ for $0 \mathrm{~h}$, and the mean percentages of the total distances of the wound areas were calculated.

Invasion assay. DU145 and PC3 cells were transfected with SOS1 RNAi, AMFR RNAi and control RNAi and seeded in duplicates at $5 \times 10^{4} /$ insert in the BD BioCoat ${ }^{\mathrm{TM}}$ 24-Multiwell Tumor Invasion System (BD Biosciences) according to the manufacturer's recommendations. After a 20-h incubation, inserts were transferred to 24-well plates containing fluorescent dye calcein AM (Molecular Probes) at $4 \mathrm{mg} / \mathrm{ml}$ in Hank's Balance Salt Solution and incubated in an incubator at $37^{\circ} \mathrm{C}$ in $5 \% \mathrm{CO}_{2}$ for $1.5 \mathrm{~h}$. Plates were read at excitation $485 \mathrm{~nm} / \mathrm{emission} 530 \mathrm{~nm}$ in an Applied Biosystems CytoFluor $^{\circledR} 4000$ multi-well plate reader.

\section{Results}

Survival, migration and invasion genes are upregulated in prostate cancer epithelial cells from African-American men. To investigate potential biological differences in epithelial cells in ethnic populations, we established primary cell cultures from prostate tumors resected from AA and EA men as described $(25,26)$. Cultured cells, showing typical 
Table I. Clinical characteristics of the study population.

\begin{tabular}{|c|c|c|c|c|}
\hline Category & All cases $(n=27)$ & African-American $(n=14)$ & European-American $(n=13)$ & P-value ${ }^{a}$ \\
\hline Age at prostatectomy, years & $60.4(42.2-75.6)$ & $61.4(46.1-71.6)$ & $60.2(42.2-75.6)$ & $0.708^{\mathrm{a}}$ \\
\hline \multicolumn{5}{|l|}{ Pathologic stage } \\
\hline $\mathrm{pT} 2, \mathrm{n}$ & 14 & 7 & 7 & $0.712^{\mathrm{b}}$ \\
\hline $\mathrm{pT} 3, \mathrm{n}^{\mathrm{c}}$ & 12 & 7 & 5 & \\
\hline \multicolumn{5}{|l|}{ Gleason's sum } \\
\hline$<7(5-6), \mathrm{n}$ & 10 & 4 & 6 & $0.440^{\mathrm{b}}$ \\
\hline$\geq 7(7-9), \mathrm{n}$ & 17 & 10 & 7 & \\
\hline \multicolumn{5}{|l|}{ Seminal vesicle invasion ${ }^{c}$} \\
\hline No, $\mathrm{n}$ & 23 & 11 & 12 & $0.225^{\mathrm{b}}$ \\
\hline Yes, $\mathrm{n}$ & 3 & 3 & 0 & \\
\hline \multicolumn{5}{|l|}{ Lymph node invasion $^{c}$} \\
\hline No, $\mathrm{n}$ & 16 & 11 & 5 & $0.530^{\mathrm{b}}$ \\
\hline Yes, $\mathrm{n}$ & 3 & 3 & 0 & \\
\hline \multicolumn{5}{|l|}{ Surgical margin status ${ }^{\mathrm{c}}$} \\
\hline Negative, $\mathrm{n}$ & 17 & 7 & 10 & $0.110^{\mathrm{b}}$ \\
\hline Positive, $\mathrm{n}$ & 9 & 7 & 2 & \\
\hline
\end{tabular}

P-value, difference between African-Americans and European-Americans. ${ }^{a t-t e s t, ~}{ }^{b}$ Fisher's exact test: all tests were two-sided. ${ }^{c}$ Cases with unknown status are not included.

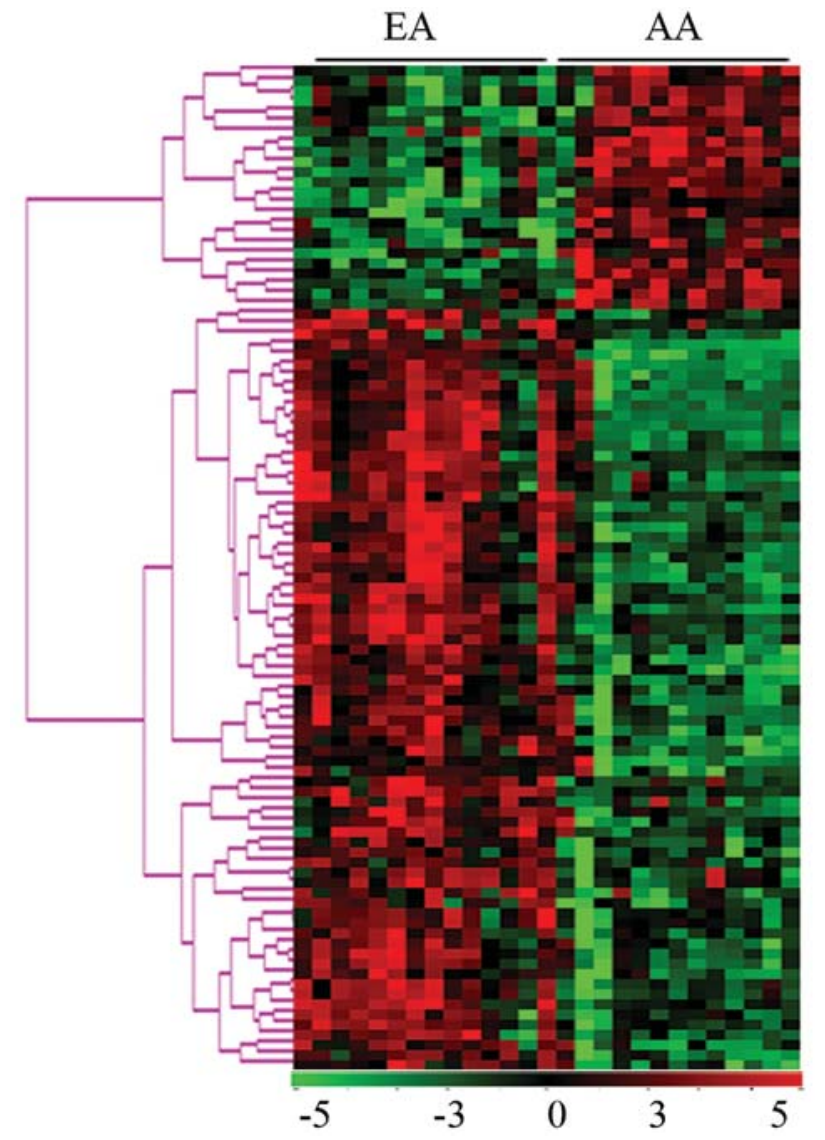

Figure 1. Heatmap of upregulated and downregulated genes with a $>1.5$-fold change in AA and EA. Genes are ordered according to their cluster determined by the $k$-means algorithm. The first 14 cell strains are from AA men, the other 13 cell strains are from EA men. Green, lower expression; red, higher expression. epithelial cell morphology were selected for gene expression profiling (14 AA and 13 EA cell cultures). Table I shows matching of the two cohorts of patients by age, tumor stage, Gleason's score, seminal vesicle and lymph node involvement. Microarray data analysis identified 382 differentially expressed genes satisfying the selection criteria of $\mathrm{p} \leq 0.001$ and FDR $\leq 0.005(0.5 \%)$ (GSE17356). Supervised hierarchical cluster analysis showed that 67 genes were increased $>1.5$-fold in AA and 25 genes were increased $>1.5$-fold in EA and partitioned the two ethnic groups as demonstrated in the heatmap (Fig. 1). qRT-PCR for the selected genes, such as autocrine motility factor receptor (AMFR), metastasisassociated 1 family, member 2 (MTA2), son of sevenless 1 (SOS1), cyclin D2 (CCND2), cathepsin B (CTSB) and homeodomain-interacting protein kinase 3 (HIPK3), confirmed their higher expression levels in prostate cancer epithelial cells from AA men (Fig. 2). In addition, immunohistochemical analyses of normal prostate tissues and high-grade prostate carcinomas demonstrated that the genes identified in our study, such as AMFR, SOS1 and MTA2, were primarily expressed in epithelial cells in prostate tissues (Fig. 3). These data confirmed that cells isolated from prostatectomy specimens were enriched for the genes differentially expressed in the epithelial component of the prostate tumors.

To determine biological pathways significantly overrepresented in prostate cancer epithelial cells from AA men, the 92 differentially expressed genes with a 1.5 fold cut-off were analyzed using DAVID software (29). The identified biological processes included signal transduction, cell communication, focal adhesion, cell cycle and apoptosis (Table II). These same pathways were overrepresented in the study reporting comparisons of tumor tissues (22). While the 


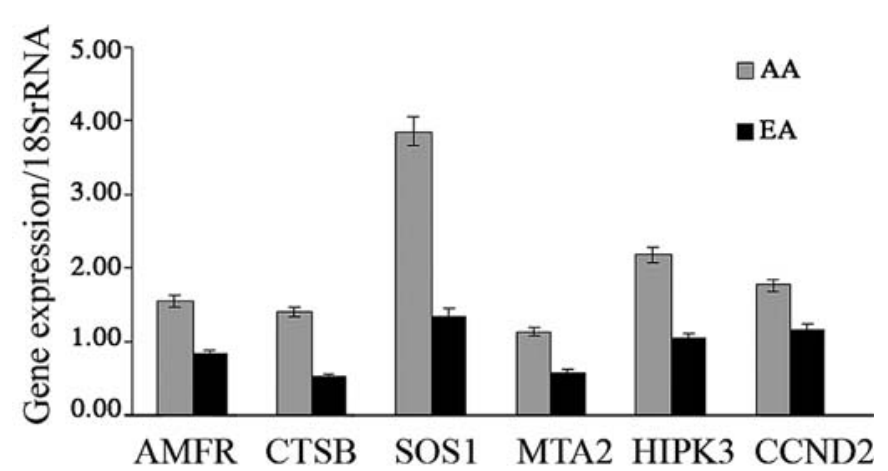

Figure 2. Differential gene expression in prostate epithelial cells from African-American (AA) and European-American (EU) men. qRT-PCR expression analysis of AMFR, CTSB, SOS1, MTA2, HIPK3 and CCND2 normalized by $18 \mathrm{~S}$ rRNA. Each bar represents a mean of three independent experiments for one cell line; bars represent SD.

Table II. Statistically significantly $(\mathrm{p}<0.05)$ altered gene ontology biological process terms in AA male-altered genes.

\begin{tabular}{lccc}
\hline GO term/KEGG & $\begin{array}{c}\text { Term hits } \\
\text { (of 92) }\end{array}$ & P-value & $\begin{array}{c}\text { Enrichment } \\
\text { score }\end{array}$ \\
\hline Signal transduction & 27 & $4.2 \mathrm{E}-2$ & 2.00 \\
Cell communication & 30 & $2.4 \mathrm{E}-2$ & 2.00 \\
Apoptosis & 8 & $9.8 \mathrm{E}-3$ & 0.73 \\
Cell cycle & 10 & $3.4 \mathrm{E}-2$ & 2.00 \\
Focal adhesion & 8 & $2.4 \mathrm{E}-4$ & 2.04 \\
Prostate cancer & 5 & $2.4 \mathrm{E}-3$ & 2.04 \\
MAPK signaling & 7 & $7.0 \mathrm{E}-4$ & 1.99 \\
Wnt signaling & 7 & $2.3 \mathrm{E}-6$ & 2.07 \\
\hline
\end{tabular}

Normal
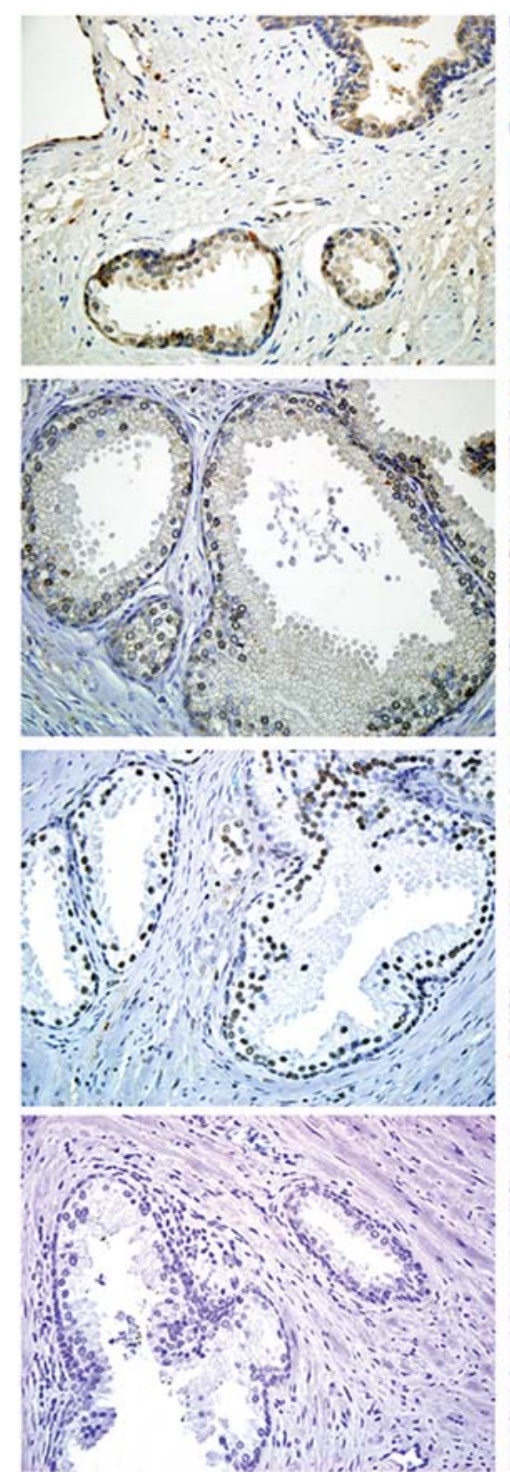

PCa
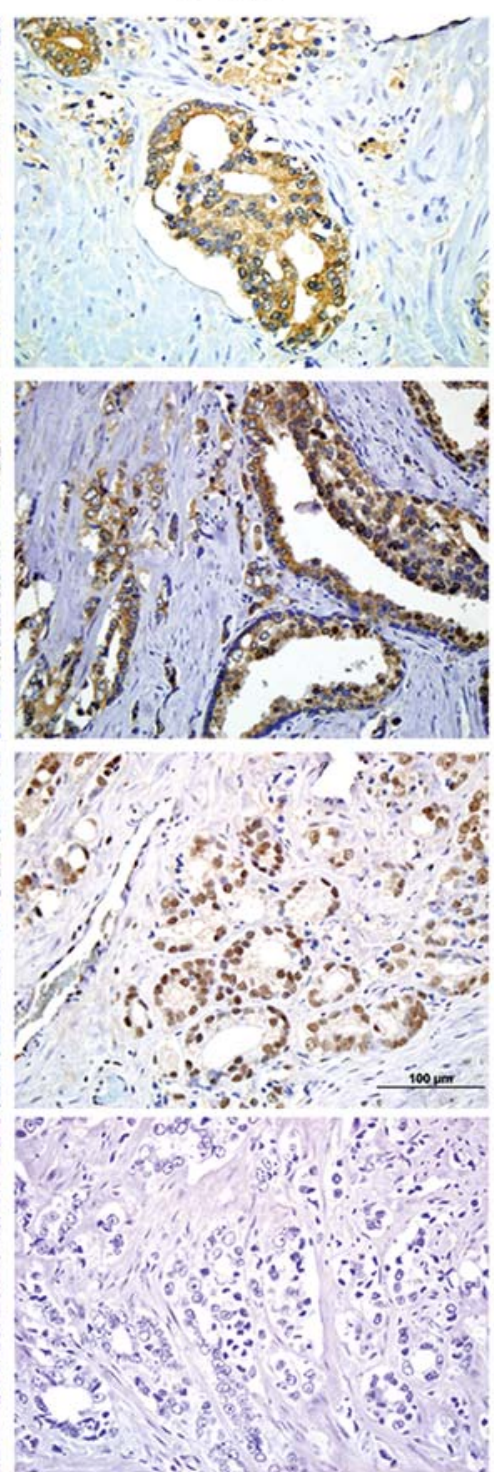

\section{AMFR}

\section{SOS1}

\section{MTA2}

\section{IgG}

Figure 3. AMFR, SOS1 and MTA2 are overexpressed in clinical prostate cancer tissue specimens. Paraffin-embedded tissue sections of human normal prostate and prostate cancer specimens were immunostained with a polyclonal antibody against human AMFR, SOS1 and MTA2. Diaminobenzidine tetrachloride (DAB) and Mayer's hematoxylin were used as chromogenic substrates and counter stains, respectively. Intense AMFR, SOS1 and MTA2 immunoreactivity was noted in epithelial cells. AMFR and SOS1 immunostaining was observed in the cytoplasm, whereas MTA2 immunostaining was detected in the nuclei (original magnification x40). Subtype-specific pure rabbit IgG was used as a negative control. 
Table III. Differential gene expression of metastasis-, migration- and invasion-related genes.

\begin{tabular}{llcc}
\hline Gene symbol & \multicolumn{1}{c}{ Description } & FC (AA vs.EA) & Parametric p-value \\
\cline { 2 - 2 } & Autocrine motility factor receptor & 4.2 & $<1 \mathrm{e}-07$ \\
AMSB & Cathepsin B & 2.5 & 0.0001552 \\
CTNNB1 & Catenin (cadherin-associated protein), B 1, 88 kDa & 1.9 & 0.0000002 \\
SOS1 & Son of sevenless homolog 1 (Drosophila) & 1.9 & $<1 \mathrm{e}-07$ \\
MTA2 & Metastasis-associated 1 family, member 2 & 1.6 & 0.0000023 \\
AXL & AXL receptor tyrosine kinase & 1.6 & 0.0006603 \\
PLA2G4C & Phospholipase A2, group IVC (cytosolic, calcium-independent) & 1.7 & 0.0008874 \\
ARPC4 & Actin related protein 2/3 complex, subunit 4, 20 kDa & 1.6 & 0.0000138 \\
PTP4A1 & Protein tyrosine phosphatase type IVA, member 1 & 1.6 & $9.07 \mathrm{E}-05$ \\
PPFIBP1 & PTPRF interacting protein, binding protein 1 (liprin B 1) & 1.6 & $3.92 \mathrm{E}-05$ \\
MARCKS & Myristoylated alanine-rich protein kinase C substrate & 1.6 & $2.38 \mathrm{E}-05$ \\
JUN & jun oncogene & 1.6 & $2.30 \mathrm{E}-06$ \\
PKN2 & Protein kinase N2 & 1.6 & $1.50 \mathrm{E}-06$ \\
LAMP1 & Lysosomal-associated membrane protein 1 & 1.5 & 0.0000271 \\
CTTN & Cortactin & 1.5 & 0.0000111 \\
CRKL & V-crk sarcoma virus CT10 oncogene homolog (avian)-like & 1.5 & 0.0000159 \\
PKP1 & Plakophilin 1 (ectodermal dysplasia/skin fragility syndrome) & 1.5 & 0.0001119 \\
\hline
\end{tabular}

Table IV. Genes detected in two independent studies.

\begin{tabular}{|c|c|c|c|c|c|c|c|}
\hline \multirow[b]{2}{*}{ Gene symbol } & \multirow[b]{2}{*}{ Description } & \multicolumn{3}{|c|}{ Our study } & \multicolumn{3}{|c|}{ Wallace et al, 2008 (22) } \\
\hline & & $\mathrm{FC}$ & P-value & FDR & $\mathrm{FC}$ & P-value & FDR \\
\hline AMFR & Autocrine motility factor receptor & 4.2 & $1.0 \mathrm{E}-07$ & 0 & 1.9 & $2.4 \mathrm{E}-05$ & 0 \\
\hline PSPH & Phosphoserine phosphatase & 3.4 & $1.0 \mathrm{E}-07$ & 0 & 4.6 & $1.0 \mathrm{E}-11$ & 0 \\
\hline CRYBB2 & Crystallin, B B2 & 2.4 & $1.0 \mathrm{E}-07$ & 0 & 3.0 & $1.3 \mathrm{E}-11$ & 0 \\
\hline SOS1 & Son of sevenless homolog 1 (Drosophila) & 1.9 & $1.0 \mathrm{E}-07$ & 0 & 1.4 & $1.3 \mathrm{E}-03$ & 2 \\
\hline CTNNB1 & Catenin (cadherin-associated protein), $\beta 1,88 \mathrm{kDa}$ & 1.9 & $1.0 \mathrm{E}-07$ & 0 & 1.3 & 4.1E-07 & 0 \\
\hline CCND1 & Cyclin D1 & 1.5 & $1.0 \mathrm{E}-07$ & 0 & 1.2 & $3.0 \mathrm{E}-02$ & 16 \\
\hline HCLS1 & Hematopoietic cell-specific Lyn substrate 1 & 1.5 & $2.9 \mathrm{E}-05$ & 0 & 1.4 & 7.9E-03 & 6 \\
\hline SLC7A5 & $\begin{array}{l}\text { Solute carrier family } 7 \text { (cationic amino acid } \\
\text { transporter, y+ system), member } 5\end{array}$ & 1.5 & $8.2 \mathrm{E}-04$ & 0 & 1.3 & $3.0 \mathrm{E}-02$ & 16 \\
\hline ARTS-1 & $\begin{array}{l}\text { Type } 1 \text { tumor necrosis factor receptor shedding } \\
\text { aminopeptidase regulator }\end{array}$ & 1.5 & $2.9 \mathrm{E}-05$ & 0 & 1.3 & $3.8 \mathrm{E}-03$ & 5 \\
\hline SOCS1 & Suppressor of cytokine signaling 1 & 1.5 & 2.9E-05 & 0 & 1.3 & $1.0 \mathrm{E}-02$ & 10 \\
\hline ISG20 & Interferon stimulated exonuclease gene $20 \mathrm{kDa}$ & 1.4 & $5.5 \mathrm{E}-04$ & 0 & 1.3 & $8.2 \mathrm{E}-03$ & 6 \\
\hline CROCCL1 & Ciliary rootlet coiled-coil, rootletin-like 1 & 1.3 & $1.6 \mathrm{E}-06$ & 0 & 1.3 & 7.2E-03 & 6 \\
\hline FLI1 & Friend leukemia virus integration 1 & 1.3 & 2.7E-04 & 0 & 1.3 & $2.0 \mathrm{E}-02$ & 13 \\
\hline RPL47A & Ribosomal protein L37a & 0.6 & $1.0 \mathrm{E}-07$ & 0 & 0.8 & $1.0 \mathrm{E}-02$ & 20 \\
\hline ADI1 & Acireductone dioxygenase 1 & 0.5 & $1.0 \mathrm{E}-07$ & 0 & 0.7 & $1.2 \mathrm{E}-04$ & 0 \\
\hline
\end{tabular}

tumor tissue analysis demonstrated overrepresentation of immune response processes, these biological processes were absent in our study consistent with our focus on gene expression in epithelial cancer cells. Closer examination of the expression data revealed that tumor cells from AA showed increases in expression of genes involved in survival, proliferation, migration, invasion and metastases (Table III). We found that 13 genes upregulated and 2 genes down- regulated in prostate cancer of AA men were common between Wallace et al (22) and our studies (Table IV). Among genes upregulated in both studies were PSPHL (probe set 205048_s_at) and CRYBB2 (probe set 206777_s_at). According to Wallace et al, this two-gene signature accurately differentiates between tumor tissues from African-American and European-American patients, but not between nontumorous tissues providing additional validation for our 


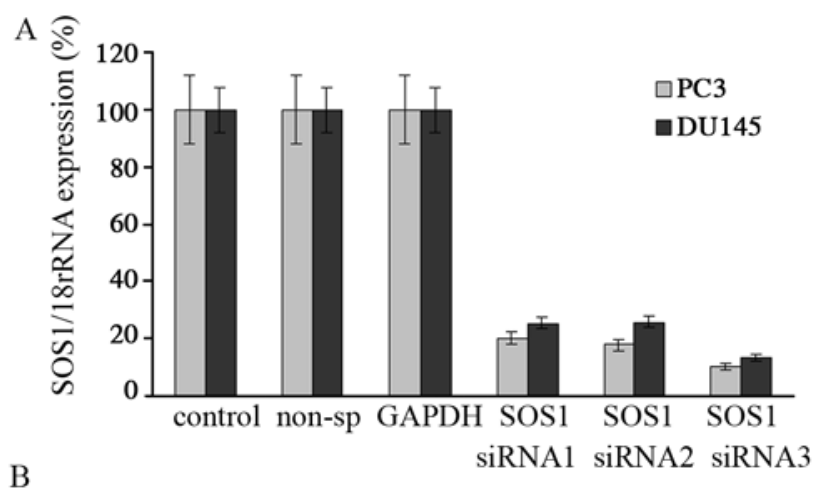

D

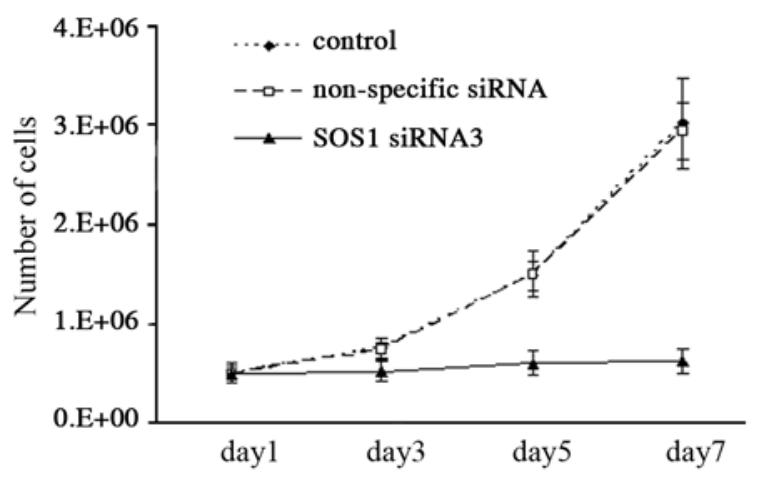

E
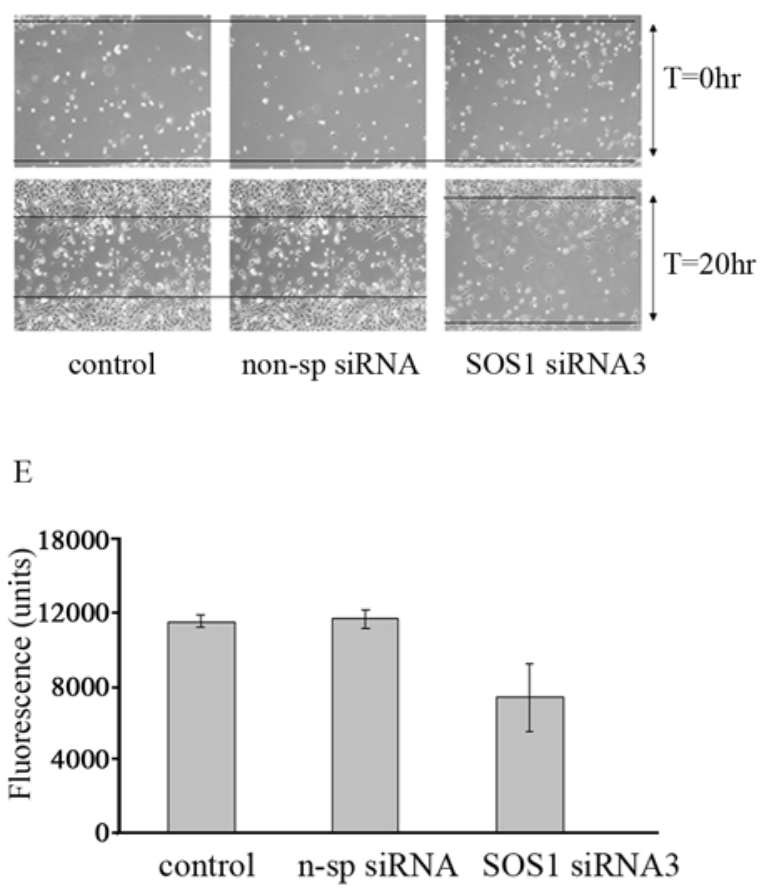

$\mathrm{C}$

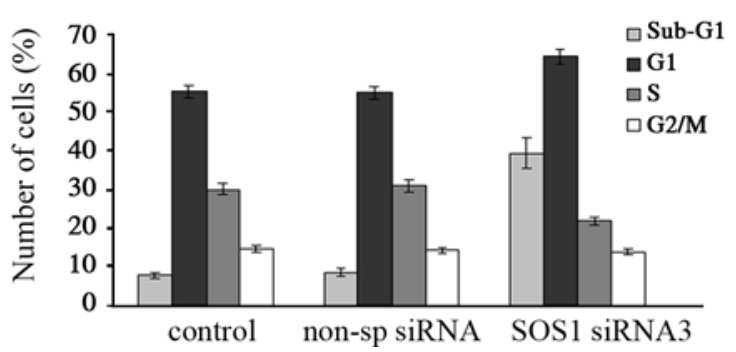

Figure 4. Decrease in SOS1 levels causes inhibition of prostate cancer cell proliferation, survival and invasion. (A) Levels of SOS1 were downregulated using 3 different stealth siRNAs. SOS1 mRNA levels in PC3 and DU145 prostate cancer cell lines were measured by qRT-PCR $24 \mathrm{~h}$ after transfection with RNAi and normalized against 18S rRNA levels. (B) Cell growth curves were obtained as follows: 2 days after transfection, 500,000 cells were plated in 100-mm dishes in triplicates; cells were trypsinized and counted every 2 days. The graph is shown for DU145 cells. (C) Cell cycle analyses were performed on DU145-transfected cells fixed with EtOH 5 days after transfection. (D) Cells were plated in 6-well plates and transfected with non-specific siRNA or SOS1 siRNA3 in triplicates (control cells were left untreated). After cell cultures reached 100\% confluence, cells were starved for $24 \mathrm{~h}$, and a scratch was made. Images were captured immediately $(\mathrm{T}=0 \mathrm{~h})$ and $20 \mathrm{~h}$ after making a scratch $(\mathrm{T}=20 \mathrm{~h})$. (E) Invasion assays were performed 2 days after transfection. DU145 cells were plated in 24-well FluoroBlock plates in duplicates and after $20 \mathrm{~h}$ were stained with calcein AM. Fluorescence readings of cells migrating through the pores to the lower chamber were taken with a plate reader at 485 -nm excitation and 530-nm emission

system. Notably, the use of cell cultures allowed determination of differential expression of common genes with higher confidence (Table IV). This suggests that some genes identified in our study may have been missed in the analyses of tumor tissues.

KEGG pathway database analyses of differentially expressed genes in tumor tissue revealed that 7 upregulated genes were closely associated with the MAPKK cascade, deregulated in the epithelial cells from prostate cancers of AA men (Table II). Recently, an aberrant mitogen-activated protein kinase (MAPK) pathway has emerged as one of the key events in the multistep nature of prostate tumorigenesis and progression $(31,32)$. An upstream activator of the MAPK signaling pathway, SOS1, was 2-fold upregulated in prostate cancer epithelial cells from AA men (Fig. 2). These data provide a rationale for further studies of the roles of SOS1 in prostate cancer progression, in particular in AA men.
SOS1 increases proliferation, migration and invasion in established model human prostate cancer cells. To determine how SOS1 may affect critical characteristics of prostate cancer cell behavior we knocked down levels of SOS1 in prostate cancer DU145 and PC3 cells (Fig. 4A) and measured proliferation, migration and invasion. The choice of cell lines was dictated by the lack of prostate cancer epithelial cell lines derived from AA patients and the aggressive phenotype of both PC3 and DU145 cells (33). Decreases in SOS1 levels inhibited growth of both PC3 and DU145 prostate cancer cells (Fig. 4B). Cell cycle analysis showed that knockdown of SOS1 causes G0/G1 phase cell cycle arrest and triggers cell death as suggested by increased numbers of cells in the sub-G1 phase (Fig. 4C). The wound healing and BD BioCoat Tumor Invasion assays demonstrated that decreases in SOS1 levels inhibit migration and invasion of prostate cancer cells (Fig. 4D and E). Decreases in SOS1 levels diminished levels 


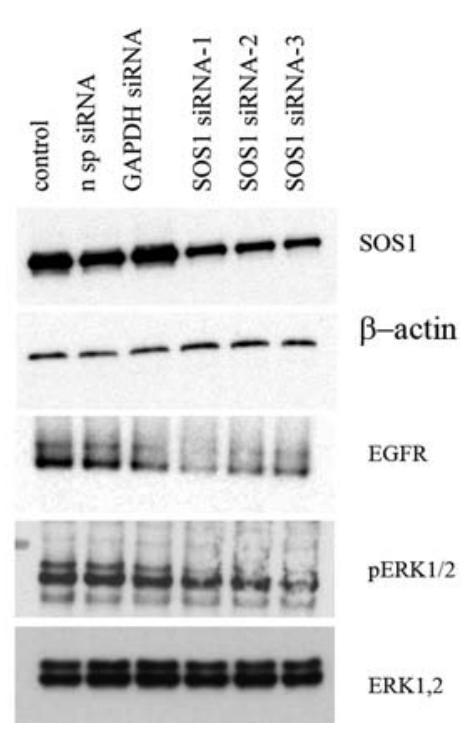

Figure 5. SOS1 RNAi knockdown decreases levels of pERK and EGFR in prostate cancer DU145 cells. Levels of pERK and EGFR were measured $48 \mathrm{~h}$ after transfection with non-specific scrambled siRNA (n sp siRNA), GAPDH siRNA, and SOS1 siRNA-1, -2 and -3, in the whole DU145 cell protein extracts. The membranes were re-blotted with antibody against $B$-actin and ERK for loading control, and with antibody against SOS1 to demonstrate knockdown efficiency.

of phospho-ERK1/2. In addition, SOS1 siRNA downregulated levels of EGFR in DU145 prostate cancer cells (Fig. 5). These events may contribute to decreased survival and migration of prostate cancer cells, since the Ras-MEKERK and EGFR signaling pathways can sustain growth, migration and invasion $(33,34)$. Therefore, increases in the levels of these proteins may contribute to prostate cancer aggressiveness in AA men.

Elevated SOS1 expression correlates with high Gleason's sum. Gleason's sum of tumor tissues has been shown to correlate with clinical aggressiveness of prostate cancers. We reasoned that gene products contributing to prostate cancer aggressiveness should also show differential presence in tissues with a higher Gleason's sum. To determine how expression of SOS1 correlates with prostate cancer aggressiveness, we analyzed protein expression in a prostate carcinoma tissue microarray containing 30 samples of prostate carcinoma with various Gleason's sums and 3 samples of benign tissue. Moderate and strong expression levels of SOS1 protein were observed in tissues with Gleason's sum $\geq 7$, whereas benign tissues and prostate tumors with Gleason's sum 6 showed only weak expression of SOS1 (Table V). There was no correlation between Gleason's sum and the number of cells expressing SOS1. We interpret this finding to support a role for SOS1 in prostate cancer aggressiveness and suggest SOS1 as a potential biomarker suitable for further evaluation in prostate cancers from AA men.

\section{Discussion}

We analyzed primary prostate cancer cells in culture to identify differentially expressed genes in the epithelial component of cancers in AA and EA men. This approach allows simplification of epithelial cell analyses, free of
Table V. Expression of SOS1 in prostate carcinomas with different Gleason's scores.

\begin{tabular}{lcccc}
\hline $\begin{array}{l}\text { Gleason's } \\
\text { sum }\end{array}$ & $\begin{array}{c}\text { No. of } \\
\text { samples }\end{array}$ & Negative & $\begin{array}{c}\text { Weak } \\
(+)\end{array}$ & $\begin{array}{c}\text { Moderate/strong } \\
(++/+++)\end{array}$ \\
\hline Benign & 3 & 2 & 1 & \\
$<7$ & 7 & & 7 & \\
$\geq 7$ & 23 & 3 & 11 & 9 \\
\hline
\end{tabular}

interactions with stroma and inflammatory cells, unavoidable in studies of prostate cancer tissues. Primary cultures are widely used to investigate the disease-specific biology of prostate cancer and benign prostatic hyperplasia (35). Study of gene expression profiles using Affymetrix Human Cancer G110 Array Chips containing approximately 1900 cancerrelated genes did not show consistent overexpression of any gene in cancer cells compared to normal prostate epithelial cells (35). Using genome-wide expression profiling, we demonstrated that 17 genes related to processes associated with growth, migration, invasion and metastases, including AMFR, SOS1, MTA2, CTSB, CTNNB1 and AXL, were upregulated in AA epithelial cells. In addition, 10 genes drive cell cycle progression, including cyclin D1 and D2, HIPK3 and JUN. Some of these genes were detected previously in the study by Wallace et al, but with lower confidence based on p-value and false discovery rate (22). Immunohistological staining demonstrated expression of AMFR, SOS 1 and MTA2 in prostate cancer epithelial cells and not in stromal cells. Taken together, our data suggest that studies of gene expression in epithelial cell cultures offer greater sensitivity than in prostate tumor tissue in identifying differences specific to malignant epithelial cells.

We observed that SOS1, activator of Ras/MAPK, is upregulated in AA prostate cancer cells. This may underlie MAPK signaling cascade deregulation in AA prostate cancer cells, as predicted by the bioinformatics analysis of microarray data. The Ras/MAPK signaling cascade represents a pivotal molecular circuitry for prostate cancer evolution, driving cell proliferation and enhancing cell migration, invasion and metastases $(32,36,37)$. It has been previously shown that inhibition of ERK signaling with small molecule inhibitors or siRNA inhibited prostate cancer cell proliferation (34), grossly impaired clonogenicity and invasion through Matrigel (33). As an activator of Ras and hence MAPK signaling, SOS1 may be a promising cancer therapy target. Here, we demonstrated that SOS1 siRNA knockdown decreases cell survival and proliferation, migration and invasion in prostate cancer cells. The mechanism for such an inhibition, at least partially, relies on inhibition of ERK1/2 phosphorylation. We propose that increased levels of SOS1 may contribute to prostate cancer cell proliferation and migration through activation of ERK signaling. The tissue microarray data suggest that increased expression of SOS1 correlates with a higher Gleason's score, and hence with prostate cancer aggressiveness. Further correlation of SOS1 expression and ERK1/2 activation in prostate carcinomas from AA men is underway to understand the molecular 
mechanism by which SOS1 promotes cancer progression in AA men and to establish the paradigm for anticancer drug development.

In addition, we detected enhanced expression of AMFR in prostate cancers from $\mathrm{AA}$, which was previously detected in the study by Wallace et al (22). The biological functions of AMFR relate to migration and metastases. Stimulation of AMFR by its ligand autocrine motility factor alters cellular adhesion, proliferation, motility, and apoptosis. AMFR upregulation correlates with more advanced tumor stage and decreased survival for cancers of the lung, esophagus, stomach, colon, rectum, liver and skin (38). AMFR also serves as an independent predictor of poor disease prognosis in these various tumor types (38). We found that a decrease in AMFR levels with siRNA induces death in prostate cancer cells and inhibits their migration (data not shown). Downstream signaling mechanisms activated by AMFR are not completely understood. Recently, a role for AMFR in sarcoma metastasis has been suggested through targeting of the transmembrane metastasis suppressor, KAI1, for degradation (39). Notably, KAI1 protein expression was downregulated in more than $70 \%$ of primary prostate cancers, and more than $90 \%$ of metastatic prostate cancers $(40,41)$. This suggests the possibility that upregulation of AMFR in prostate cancers impacts degradation of KAI1 to contribute to disease progression through increased survival and migration. Further studies are necessary to establish a role of AMFR in prostate cancer and to validate it as a molecular target for anticancer therapy.

In summary, we investigated gene expression in prostate cancer to address racial health disparity. That AA men present with more advanced prostate cancers at diagnosis and demonstrate more aggressive disease progression than do EA men has been supported by epidemiological studies $(4,16)$. Health disparity investigations have generally focused on access to health care and socioeconomic status; however, disparity in prognosis is observed even for patients participating in health maintenance organizations, in which access to health care is comparable for AA and EA patients (16). AA males whose prostate surgical margins contain cancer cells seem to have greater biological aggressiveness of residual disease, a higher clinical recurrence rate of disease, and lower survival rates even after radical prostatectomy (42). Our approach does not include epithelial-stromal or -inflammatory cell interactions, which have been shown to contribute to the carcinogenic process (43). However, our approach provides insight into prostate cancer epithelial cells, the presumed vehicle of the malignant process. Our data identified SOS1 and AMFR as representative biological factors of cancer aggressiveness consistent with the clinical findings of higher stages at diagnosis and more aggressive clinical courses of prostate cancer in African-American as compared to EuropeanAmerican patients. Confirmation of these molecules in a larger prospective study is needed to validate the candidate genes as biomarkers or therapeutic targets.

\section{Acknowledgements}

We thank Eva Permaul and Deborah L. Berry from The Lombardi Comprehensive Cancer Center Histopathology and Tissue Shared Resource for their excellent assistance and the Human Tissue Bank for providing prostate tissue samples.
This study was supported by the National Institute of Health (grant no. PO1 CA74175 to A.D.), and a Department of Defense Prostate Cancer Research Program (grant no. PC030694 to J.S.R.).

\section{References}

1. Jemal A, Siegel R, Ward E, Murray T, Xu J and Thun MJ: Cancer statistics, 2007. CA Cancer J Clin 57: 43-66, 2007.

2. Hsing AW, Tsao L and Devesa SS: International trends and patterns of prostate cancer incidence and mortality. Int J Cancer 85: 60-67, 2000.

3. Weir HK, Thun MJ, Hankey BF, Ries LA, Howe HL, Wingo PA, Jemal A, Ward E, Anderson RN and Edwards BK: Annual report to the nation on the status of cancer, 1975-2000, featuring the uses of surveillance data for cancer prevention and control. J Natl Cancer Inst 95: 1276-1299, 2003.

4. Evans S, Metcalfe C, Ibrahim F, Persad R and Ben-Shlomo Y: Investigating Black-White differences in prostate cancer prognosis: A systematic review and meta-analysis. Int J Cancer 123: 430-435, 2008.

5. Evans S, Ben-Shlomo Y and Persad R: Prostate cancer in Black and White men: are there differences in risk or prognosis? BJU Int 92: 878-879, 2003.

6. Dhanasekaran SM, Barrette TR, Ghosh D, Shah R, Varambally S, Kurachi K, Pienta KJ, Rubin MA and Chinnaiyan AM: Delineation of prognostic biomarkers in prostate cancer. Nature 412: 822-826, 2001.

7. DeChello LM, Gregorio DI and Samociuk H: Race-specific geography of prostate cancer incidence. Int J Health Geogr 5: $59,2006$.

8. Ben-Shlomo Y, Evans S, Ibrahim F, Patel B, Anson K, Chinegwundoh F, Corbishley C, Dorling D, Thomas B, Gillatt D, Kirby R, Muir G, Nargund V, Popert R, Metcalfe C and Persad R: The risk of prostate cancer amongst black men in the United Kingdom: the PROCESS cohort study. Eur Urol 53: 99-105, 2008.

9. Chinegwundoh F, Enver M, Lee A, Nargund V, Oliver T and Ben-Shlomo Y: Risk and presenting features of prostate cancer amongst African-Caribbean, South Asian and European men in northeast London. BJU Int 98: 1216-1220, 2006.

10. Platz EA, Rimm EB, Willett WC, Kantoff PW and Giovannucci E: Racial variation in prostate cancer incidence and in hormonal system markers among male health professionals. J Natl Cancer Inst 92: 2009-2017, 2000.

11. Tricoli JV, Winter DL, Hanlon AL, Raysor SL, Watkins-Bruner D, Pinover WH and Hanks GE: Racial differences in insulin-like growth factor binding protein-3 in men at increased risk of prostate cancer. Urology 54: 178-182, 1999.

12. Winters SJ, Brufsky A, Weissfeld J, Trump DL, Dyky MA and Hadeed V: Testosterone, sex hormone-binding globulin, and body composition in young adult African American and Caucasian men. Metabolism 50: 1242-1247, 2001.

13. Wu AH, Whittemore AS, Kolonel LN, John EM, Gallagher RP, West DW, Hankin J, Teh CZ, Dreon DM and Paffenbarger RS Jr: Serum androgens and sex hormone-binding globulins in relation to lifestyle factors in older African-American, white, and Asian men in the United States and Canada. Cancer Epidemiol Biomarkers Prev 4: 735-741, 1995.

14. Freedman ML, Haiman CA, Patterson N, McDonald GJ, Tandon A, Waliszewska A, Penney K, Steen RG, Ardlie K, John EM, Oakley-Girvan I, Whittemore AS, Cooney KA, Ingles SA, Altshuler D, Henderson BE and Reich D: Admixture mapping identifies 8q24 as a prostate cancer risk locus in African-American men. Proc Natl Acad Sci USA 103: 14068-14073, 2006.

15. Amundadottir LT, Sulem P, Gudmundsson J, Helgason A, Baker A, Agnarsson BA, Sigurdsson A, Benediktsdottir KR, Cazier JB, Sainz J, Jakobsdottir M, Kostic J, Magnusdottir DN, Ghosh S, Agnarsson K, Birgisdottir B, Le Roux L, Olafsdottir A, Blondal T, Andresdottir M, Gretarsdottir OS, Bergthorsson JT, Gudbjartsson D, Gylfason A, Thorleifsson G, Manolescu A, Kristjansson K, Geirsson G, Isaksson H, Douglas J, Johansson JE, Balter K, Wiklund F, Montie JE, Yu X, Suarez BK, Ober C, Cooney KA, Gronberg H, Catalona WJ, Einarsson GV, Barkardottir RB, Gulcher JR, Kong A, Thorsteinsdottir U and Stefansson K: A common variant associated with prostate cancer in European and African populations. Nat Genet 38: 652-658, 2006. 
16. Powell IJ: Epidemiology and pathophysiology of prostate cancer in African-American men. J Urol 177: 444-449, 2007.

17. Ellis L and Nyborg H: Racial/ethnic variations in male testosterone levels: a probable contributor to group differences in health. Steroids 57: 72-75, 1992.

18. Gaston KE, Kim D, Singh S, Ford OH III and Mohler JL: Racial differences in androgen receptor protein expression in men with clinically localized prostate cancer. J Urol 170: 990-993, 2003.

19. Ross R, Bernstein L, Judd H, Hanisch R, Pike M and Henderson B: Serum testosterone levels in healthy young black and white men. J Natl Cancer Inst 76: 45-48, 1986.

20. McGreevy KM, Hoel BD, Lipsitz SR and Hoel DG: Impact of nutrients on insulin-like growth factor-I, insulin-like growth factor binding protein-3 and their ratio in African American and white males. Public Health Nutr 10: 97-105, 2007.

21. Haqq C, Li R, Khodabakhsh D, Frolov A, Ginzinger D, Thompson T, Wheeler T, Carroll P and Ayala G: Ethnic and racial differences in prostate stromal estrogen receptor alpha. Prostate 65: 101-109, 2005.

22. Wallace TA, Prueitt RL, Yi M, Howe TM, Gillespie JW, Yfantis HG, Stephens RM, Caporaso NE, Loffredo CA and Ambs S: Tumor immunobiological differences in prostate cancer between African-American and European-American men. Cancer Res 68: 927-936, 2008.

23. Reams RR, Agrawal D, Davis MB, Yoder S, Odedina FT, Kumar N, Higginbotham JM, Akinremi T, Suther S and Soliman KF: Microarray comparison of prostate tumor gene expression in African-American and Caucasian American males: a pilot project study. Infect Agent Cancer 4 (Suppl 1): 3, 2009.

24. Bermudo R, Abia D, Ferrer B, Nayach I, Benguria A, Zaballos A, del Rey J, Miro R, Campo E, Martinez AC, Ortiz AR, Fernandez PL and Thomson TM: Co-regulation analysis of closely linked genes identifies a highly recurrent gain on chromosome $17 \mathrm{q} 25.3$ in prostate cancer. BMC Cancer 8: 315, 2008.

25. Yasunaga Y, Nakamura K, Ewing CM, Isaacs WB, Hukku B and Rhim JS: A novel human cell culture model for the study of familial prostate cancer. Cancer Res 61: 5969-5973, 2001.

26. Yasunaga Y, Nakamura K, Ko D, Srivastava S, Moul JW, Sesterhenn IA, McLeod DG and Rhim JS: A novel human cancer culture model for the study of prostate cancer. Oncogene 20: 8036-8041, 2001.

27. Barnard RJ, Kobayashi N and Aronson WJ: Effect of diet and exercise intervention on the growth of prostate epithelial cells. Prostate Cancer Prostatic Dis 11: 362-366, 2008.

28. Wright GW and Simon RM: A random variance model for detection of differential gene expression in small microarray experiments. Bioinformatics 19: 2448-2455, 2003.

29. Dennis G Jr, Sherman BT, Hosack DA, Yang J, Gao W, Lane HC and Lempicki RA: DAVID: Database for Annotation, Visualization, and Integrated Discovery. Genome Biol 4: P3, 2003.

30. Timofeeva OA, Plisov S, Evseev AA, Peng S, Jose-Kampfner M, Lovvorn HN, Dome JS and Perantoni AO: Serine-phosphorylated STAT1 is a prosurvival factor in Wilms' tumor pathogenesis. Oncogene 25: 7555-7564, 2006.
31. Pearson HB, Phesse TJ and Clarke AR: K-ras and Wnt signaling synergize to accelerate prostate tumorigenesis in the mouse. Cancer Res 69: 94-101, 2009.

32. Setlur SR, Royce TE, Sboner A, Mosquera JM, Demichelis F, Hofer MD, Mertz KD, Gerstein M and Rubin MA: Integrative microarray analysis of pathways dysregulated in metastatic prostate cancer. Cancer Res 67: 10296-10303, 2007.

33. Johnson TR, Khandrika L, Kumar B, Venezia S, Koul S, Chandhoke R, Maroni P, Donohue R, Meacham RB and Koul HK: Focal adhesion kinase controls aggressive phenotype of androgen-independent prostate cancer. Mol Cancer Res 6: 1639-1648, 2008

34. Carey AM, Pramanik R, Nicholson LJ, Dew TK, Martin FL, Muir GH and Morris JD: Ras-MEK-ERK signaling cascade regulates androgen receptor element-inducible gene transcription and DNA synthesis in prostate cancer cells. Int J Cancer 121: 520-527, 2007.

35. Rose A, Xu Y, Chen Z, Fan Z, Stamey TA, McNeal JE, Caldwell $\mathrm{M}$ and Peehl DM: Comparative gene and protein expression in primary cultures of epithelial cells from benign prostatic hyperplasia and prostate cancer. Cancer Lett 227: 213-222, 2005.

36. Lotan TL, Lyon M, Huo D, Taxy JB, Brendler C, Foster BA, Stadler W and Rinker-Schaeffer CW: Up-regulation of MKK4, MKK6 and MKK7 during prostate cancer progression: an important role for SAPK signalling in prostatic neoplasia. J Pathol 212: 386-394, 2007.

37. Papatsoris AG, Karamouzis MV and Papavassiliou AG: The power and promise of 'rewiring' the mitogen-activated protein kinase network in prostate cancer therapeutics. Mol Cancer Ther 6: 811-819, 2007

38. Chiu CG, St-Pierre P, Nabi IR and Wiseman SM: Autocrine motility factor receptor: a clinical review. Expert Rev Anticancer Ther 8: 207-217, 2008.

39. Tsai YC, Mendoza A, Mariano JM, Zhou M, Kostova Z, Chen B, Veenstra T, Hewitt SM, Helman LJ, Khanna C and Weissman AM: The ubiquitin ligase gp78 promotes sarcoma metastasis by targeting KAI1 for degradation. Nat Med 13: 1504-1509, 2007

40. Dong JT, Suzuki H, Pin SS, Bova GS, Schalken JA, Isaacs WB, Barrett JC and Isaacs JT: Down-regulation of the KAI1 metastasis suppressor gene during the progression of human prostatic cancer infrequently involves gene mutation or allelic loss. Cancer Res 56: 4387-4390, 1996.

41. Ueda T, Ichikawa T, Tamaru J, Mikata A, Akakura K, Akimoto S, Imai T, Yoshie O, Shiraishi T, Yatani R, Ito H and Shimazaki J: Expression of the KAI1 protein in benign prostatic hyperplasia and prostate cancer. Am J Pathol 149: 1435-1440, 1996.

42. Iselin CE, Box JW, Vollmer RT, Layfield LJ, Robertson JE and Paulson DF: Surgical control of clinically localized prostate carcinoma is equivalent in African-American and white males. Cancer 83: 2353-2360, 1998.

43. Taylor RA and Risbridger GP: Prostatic tumor stroma: a key player in cancer progression. Curr Cancer Drug Targets 8: 490-497, 2008. 